\title{
Adaptive Evolution Strategy to Enhance the Performance of Scheffersomyces stipitis for Industrial Cellulosic Ethanol Production
}

\author{
Guido F. Novelli Poisson, ${ }^{1,2}$ Ángela B. Juárez, ${ }^{3}$ Diego G. Noseda, \\ María C. Ríos de Molina, and Miguel A. Galvagno ${ }^{2}$ \\ 'Universidad de Buenos Aires, Facultad de Ingeniería, \\ Departamento de Ingeniería Química, Laboratorio de \\ Microbiología Industrial, Pabellón de Industrias, Ciudad \\ Universitaria, Buenos Aires, Argentina \\ ${ }^{2}$ Instituto de Investigaciones Biotecnológicas, Universidad \\ Nacional de San Martín-Consejo Nacional de Investigaciones \\ Científicas y Técnicas, San Martín, Buenos Aires, Argentina \\ ${ }^{3}$ Universidad de Buenos Aires, Facultad de Ciencias Exactas \\ y Naturales, Departamento de Biodiversidad y Biología \\ Experimental y Departamento de Química Biológica Buenos \\ Aires, Argentina \\ ${ }^{4}$ Universidad de Buenos Aires, Facultad de Ciencias Exactas \\ y Naturales, Departamento de Química Biológica Ciudad \\ Universitaria, Buenos Aires, Argentina
}

\section{ABSTRACT}

The use of microorganisms in industrial fermentations requires robust strains tolerant to stresses that challenge its performance during the bioprocess. One approach to obtain such a strain, adaptive evolution methodology, is carried out in this work with an emphasis on the biochemistry of stress tolerance. This work evaluated the robustness and cellulosic ethanol efficiency of an evolutionary adapted strain of Scheffersomyces stipitis NRRL Y-7124 (HAJ) obtained after successive batch cultures with increasing concentrations of acid hydrolysate lignocellulosic jojoba residue. Strain robustness was associated with its ability to tolerate stresses present along an industrial cellulosic bioethanol production process (i.e., thermal, oxidative or osmotic stress; high concentration of ethanol or phenolic compounds). Under such conditions, HAJ exhibited 4-fold higher viability and 8-fold higher vitality (metabolic performance) values than the parental strain. Whereas all stresses assayed produced a significant increase in reactive oxygen species (ROS) concentrations in Y-7124 (up to 15-fold higher than controls), in HÁJ only ethanol induced a significant rise in ROS levels, associated to variations in superoxide dismutase (SOD) and catalase (CAT) enzymatic activities. The highest increase in SOD activity was associated with ethanol stress, the most oxidative stress assayed, being 3.5-fold higher in HAJ versus Y-7124. Intracellular concentrations of cell protectants trehalose and glycogen increased significantly after stresses related to hydric deficiencies (sorbitol and ethanol), with HAJ showing a higher increase than the parental strain. Ethanol production efficiency on a non-detoxified, nonsupplemented acid-hydrolyzed lignocellulosic medium was $40 \%$ higher for HAJ versus Y-7124. Our results propose that stress cross-tolerance of this yeast is associated to its oxidative stress tolerance, and that high levels of molecules like trehalose should be a goal for obtaining a robust strain that can be used industrially.

Keywords: Scheffersomyces (Pichia) stipitis, adaptive evolution, cellulosic bioethanol production

\section{Introduction}

Scheffersomyces (Pichia) stipitis is an aerobic, Crabtreenegative yeast, well known for its capacity to ferment C5 and C6 sugars to efficiently produce ethanol and having one of the highest native abilities for xylose fermentation, with substrate yields between $0.35-0.44 \mathrm{~g} / \mathrm{g} .{ }^{1-3}$ In $S$. stipitis, ethanol production is favored under oxygen-limited (microaerobic) conditions. ${ }^{4}$ Due to its ability to ferment both C5 and C6 sugars, S. stipitis can be efficiently used for bioethanol production from lignocellulosic substrates containing large amounts of these sugars. ${ }^{5,6}$ Standard acid hydrolysis pretreatments of lignocellulosic biomass result in hydrolysates rich in hexoses (principally glucose and galactose) and pentoses (mainly xylose and arabinose). ${ }^{7}$ As a consequence of this treatment, several toxic and growth-inhibiting compounds are also produced, including furaldehydes, aliphatic acids, and phenolic compounds. ${ }^{8}$ For its industrial application, it is essential for S. stipitis to have the capacity to tolerate those inhibitors, as well as a wide variety of stress conditions. Simultaneously, it should maintain an adequate metabolic performance during the fermentative process to increase the bioconversion yield of cellulosic sugars to ethanol.

Enhancing yeast performance in the presence of inhibitors or stressors requires the selection of yeast populations with better vitality (overall physiological and metabolic fitness). Adaptive evolution allows the selection of yeast populations resistant to different stress conditions and with an expanded tolerance range. ${ }^{9-14}$ Tolerance to oxidative stress-generating reactive oxygen species (ROS) seems to be a common mechanism of multiple stress tolerance. ${ }^{9}$ ROS are generated as byproducts of cellular aerobic metabolism, ${ }^{15}$ with the three most common being superoxide $\left(\mathrm{O}_{2}^{\bullet-}\right)$, hydroxyl radical $(\mathrm{OH} \bullet)$, and hydrogen peroxide $\left(\mathrm{H}_{2} \mathrm{O}_{2}\right)$. These can damage a variety of cellular 
components, including nucleic acids, proteins and lipids, eventually leading to yeast cell death. ${ }^{16,17}$ Under normal physiological conditions, yeast can respond to ROS, overcoming oxidative stress by diverse mechanisms combining ROS scavengers such as glutathione, thioredoxins and dehydroascorbic acid, ${ }^{18-22}$ and antioxidant enzymes such as catalases (CAT), superoxide dismutase (SOD) and glutathione peroxidase. CAT and SOD are considered the most active antioxidant enzymes in response to environmentally stressful conditions, due to direct decomposition of ROS, and SOD, usually considered the first line of defense against oxidative stress. ${ }^{23-25}$ Together with the defensive mechanisms mentioned above, the non-reducing disaccharide trehalose has been shown to play a main role in yeast cell protection against a variety of stresses, including exposure to oxidative agents. ${ }^{26-29}$ Trehalose (a non-reducing disaccharide) appears to be important during both the direct stress challenge and subsequent stress recovery ${ }^{30,31}$ by stabilizing cellular structures. ${ }^{32}$ On the other hand, high trehalose levels could lead to glycolysis dysfunction, decreased pyruvate kinase activity (affecting the redox balance/homeostasis of the cell), and impaired cell growth and metabolism. ${ }^{33}$

Several studies have reported that previous yeast exposure to one mild stress condition can increase tolerance against challenges by the same, or different stress, even when applied at a higher level-a phenomenon known as stress cross-tolerance. ${ }^{14,34-37}$

Traditional ethanologenic industrial yeasts do not ferment C5 sugars and are not able to grow in concentrated lignocellulosic hydrolysates due to their high sugar concentrations $(>100 \mathrm{~g} / \mathrm{L})$ and the toxic byproducts generated during lignocellulosic substrate pretreatments. ${ }^{6}$ As mentioned, S. stipitis is one of the most viable natural pentose-fermenting yeasts available for cellulosic ethanol production. ${ }^{3}$ However, its stress tolerance needs improvement to be able to resist osmotic pressure and high ethanol concentrations. ${ }^{38}$

In view of this evidence, the objectives of this study were, first, to improve the robustness of a strain of S. stipitis in industrial bioethanol production from lignocellulosic feedstock through an adaptive evolution strategy; second, to explore whether it is possible to use this methodology to obtain a yeast cell population of $S$. stipitis co-tolerant to the different stress conditions that may be found during bioethanol industrial production; and finally, to gain insight into the relationship between oxidative stress resistance mechanisms, synthesis of stress protectant molecules, and multiple stress tolerance.

Herein we present an evolutionarily adapted S. stipitis strain in which the concomitant action of antioxidant enzymes and cell membrane-protecting molecules makes it tolerant to, among others, high ethanol and osmotic stress. These traits, together with its increased thermotolerance, make it a suitable yeast strain for economically viable industrial cellulosic bioethanol production.

\section{Materials and Methods STRAINS}

Scheffersomyces (syn Pichia) stipitis NRRL Y-7124 (USDA, Northern Regional Research Laboratory Culture Collection) was provided by Dr. C. Kurtzman and used for the adaptive evolution procedure. Both the parental wild-type strain and the adapted clone were maintained on petri dishes containing YPD medium $(1 \% \mathrm{w} / \mathrm{v}$ yeast extract, $1 \% \mathrm{w} / \mathrm{v}$ meat peptone, $2 \% \mathrm{w} / \mathrm{v}$ glucose, $2 \% \mathrm{w} / \mathrm{v}$ agar) at $4{ }^{\circ} \mathrm{C}$ and stored in glycerol $25 \% \mathrm{v} / \mathrm{v}$ at $-80 \pm 1{ }^{\circ} \mathrm{C}$.

Unless indicated otherwise, all measurements were carried out at $28 \pm 1^{\circ} \mathrm{C}$. Cell counting was performed in a Neubauer chamber mounted in saline. All submerged cultures were carried out in $250 \mathrm{~mL}$ Erlenmeyer flasks containing medium at a 1:5 medium volume to flask volume ratio, in an orbital shaker at $150 \mathrm{rpm}$. Each experiment was done in triplicate and the data presented are the average.

\section{PREPARATION OF JOJOBA CAKE HYDROLYSATE}

Residual cakes from chemical extraction of waxes from jojoba (Simmondsia chinensis) seeds-containing $11.1 \% \mathrm{w} / \mathrm{W}$ cellulose, $12.0 \% \mathrm{w} / \mathrm{w}$ hemicellulose, $16.7 \% \mathrm{w} / \mathrm{w}$ total nonstructural carbohydrate, $28.0 \%$ protein and $24.9 \% \mathrm{w} / \mathrm{w}$ ligninwere grinded to less than $1 \mathrm{~mm}$ particles. The ground residual cake was hydrolyzed in $0.5 \mathrm{~N}$ sulfuric acid with a dry weight/ volume ratio of $1: 5$, for $3 \mathrm{~h}$ at $100^{\circ} \mathrm{C}$, and filtered successively through gauze and filter paper. The $\mathrm{pH}$ of the acid hydrolysate was brought to 4.8 with $10 \mathrm{~N} \mathrm{NaOH}$ and sterilized by autoclaving. This lignocellulosic hydrolysate, identified as jojoba cake hydrolysate $(\mathrm{JCH})$, contained $\sim 4.0 \mathrm{~g} / \mathrm{L}$ of glucose (measured using an enzymatic kit from Wiener Lab, Rosario, Argentina), $\sim 40.0 \mathrm{~g} / \mathrm{L}$ of total pentoses (determined by the method described in Deschatelets and Yu), ${ }^{39} \sim 1.81 \mathrm{mg} / \mathrm{L}$ of total phenols (method adapted from Singleton et al.), ${ }^{40}$ and $\sim 1.35 \mathrm{~g} / \mathrm{L}$ furans (as described in Martinez et al). ${ }^{41}$

\section{ADAPTIVE EVOLUTION OF S. STIPITIS IN HYDROLYSATE}

The parental strain S. stipitis NRRL Y-7124 was grown on YPD medium in an orbital shaker at $150 \mathrm{rpm}$ for $24 \mathrm{~h}$. The culture was used to inoculate a $250-\mathrm{mL}$ Erlenmeyer flask containing $50 \mathrm{~mL}$ of an adaptation medium composed of yeast nitrogen base (YNB, BD Difco, Franklin Lakes, NJ) and $10 \% \mathrm{v} / \mathrm{v}$ $\mathrm{JCH}$. After $24 \mathrm{~h}$ incubation, this culture was used as inoculum for a new, $24 \mathrm{~h}$ culture with the same concentration of hydrolysate. This procedure was repeated in successive passages using increasing concentrations of hydrolysate, at $5 \%$ increments up to $90 \% \mathrm{v} / \mathrm{v}$, implying 34 culture transfers and approximately 300 generations. Cultures were started with low biomass concentration $\left(\mathrm{OD}_{600 \mathrm{~nm}} \approx 0.1\right)$ to select a cell population with better adaptability or detoxification capacity on this hydrolysate. Growth was followed spectrophotometrically $\left(\mathrm{OD}_{600 \mathrm{~nm}}\right)$ with an UV-Visible Spectrophotometer T60 PG Instrument. This growth determination method was routinely employed (unless indicated otherwise). Samples were withdrawn from the last culture in which growth occurred and stored at $-80 \pm 1^{\circ} \mathrm{C}$ in $25 \% \mathrm{v} / \mathrm{v}$ glycerol solution for further assays. The clone adapted to the JCH was named S. stipitis HAJ.

\section{TOLERANCE TO STRESS CONDITIONS}

To evaluate the robustness of the adapted clone to the hydrolysate of jojoba cake compared to its parental strain, 


\section{STRESS TOLERANCE IN ADAPTED STRAIN OF S. STIPITIS FOR BIOETHANOL PRODUCTION}

tolerance to a set of stress conditions was evaluated. The stressors studied consisted of inhibitors present in lignocellulosic hydrolysates, and others that a yeast might face in a bioethanol production process typical of alcoholic fermentation. Briefly, cultures of S. stipitis Y-7124 and HAJ (in YPD and $\mathrm{JCH}$, respectively) were diluted to obtain a final $\mathrm{OD}_{600 \mathrm{~nm}}$ of 1.0. Then, cells were washed three times with saline solution $(0.9 \% \mathrm{v} / \mathrm{v} \mathrm{NaCl})$, centrifuged at $7,500 \mathrm{~g}$ for $10 \mathrm{~min}$, and resuspended in $0.1 \mathrm{~mol} / \mathrm{L}$ potassium phosphate buffer $(\mathrm{pH} \mathrm{6.0)}$ before being subjected to the following stress conditions: ethanol (20\% v/v, $30 \mathrm{~min})$, oxidative stress $\left(0.3 \mathrm{~mol} / \mathrm{L} \mathrm{H}_{2} \mathrm{O}_{2}\right.$, $1 \mathrm{~h})$, osmotic shock $(2.5 \mathrm{~mol} / \mathrm{L}$ sorbitol, $4 \mathrm{~h})$, thermal shock $\left(55^{\circ} \mathrm{C}, 5 \mathrm{~min}\right)$ and phenolic acid $(0.6 \mathrm{~g} / \mathrm{L}$ vanillin, $1 \mathrm{~h})$. After treatments, stressors were removed by washing the cells with $0.1 \mathrm{~mol} / \mathrm{L}$ potassium phosphate buffer $(\mathrm{pH}$ 6.0) or by ending the experiment in a water bath at $25^{\circ} \mathrm{C}$. The stressors were selected due to their presence in the acid hydrolysate (phenols); for the potential use of the adapted strain in very high gravity (VHG) fermentation (osmotic stress) or in simultaneous saccharification and fermentation (SSF) (thermal stress); for their known oxidative capacity (hydrogen peroxide); or because they are products of fermentative activity (ethanol). To study the effect of these stressors, the following determinations were carried out on the treated cells: viability; vitality; antioxidant enzyme activities; intracellular concentrations of ROS, trehalose, glycogen, NAD/NADH and NADP/NADPH; and pyruvate kinase activity.

\section{CELL VIABILITY}

Serial dilutions of the stressor-treated cells were carried out with distilled water from $10^{-1}$ up to $10^{-7}$. Viability was determined in triplicate by plating $10 \mu \mathrm{L}$ of each dilution on YPD agar. After a $24 \mathrm{~h}$ incubation at $28 \pm 1^{\circ} \mathrm{C}$, colonies were counted and averaged for each dilution. Cell viability was reported as the survival percentage ${ }^{42}$ in comparison to the unstressed cells (control).

\section{CELL VITALITY}

Vitality of the treated cells was assessed to determine their metabolic performance by using the acidification power test devised by Opekarová and Sigler. ${ }^{43}$ Briefly, cells were harvested after stressor exposure by centrifugation, washed three times with saline solution, and quantified in a Neubauer chamber. Dilutions were made with sterile distilled water to reach a final concentration of $5 \times 10^{7} \mathrm{cell} / \mathrm{mL}$, and $5 \mathrm{~mL}$ of each dilution was transferred to $15 \mathrm{~mL}$ Falcon tubes. $\mathrm{pH}$ was measured every $1 \mathrm{~min}$ for $10 \mathrm{~min}$, after which a glucose solution was added to a final concentration of $1 \% \mathrm{v} / \mathrm{v}$, and $\mathrm{pH}$ measurement continued for another $10 \mathrm{~min}$. Acidification power was determined as $\mathrm{AP}=\mathrm{pH}_{\mathrm{t}=0 \mathrm{~min}}-\mathrm{pH}_{\mathrm{t}=20 \mathrm{~min}}$.

\section{OXIDATIVE PARAMETERS}

Cell free extracts were prepared using the method described by Gurdo et al. ${ }^{14}$ Intracellular ROS concentration, and CAT and SOD activities were quantified in the supernatants of the cell homogenates using methods described by Zhang, ${ }^{44} \mathrm{Aebi},{ }^{45}$ and Beauchamp and Fridovich, ${ }^{46}$ respectively.

\section{PROTEIN CONTENT}

Total soluble protein content was determined in the supernatants according to Bradford, ${ }^{47}$ using bovine serum albumin as standard (Sigma Aldrich, St. Louis, MO).

\section{TREHALOSE AND GLYCOGEN MEASUREMENT}

Intracellular trehalose and glycogen were quantified as described in Parrou et al. ${ }^{48}$ Briefly, $1.0 \times 10^{8}$ cells of each treated culture were centrifuged in $1.5 \mathrm{~mL}$ tubes at $20,000 \mathrm{x} \mathrm{g}$ for $1 \mathrm{~min}$. After discarding the supernatants, pellets were washed with $1 \mathrm{~mL}$ saline solution and centrifuged again. Pellets were resuspended in $125 \mu \mathrm{L}$ of $0.25 \mathrm{~mol} / \mathrm{L} \mathrm{Na}_{2} \mathrm{CO}_{3}$ solution and incubated $3 \mathrm{~h}$ at $95 \pm 1^{\circ} \mathrm{C}$. After cooling to room temperature, $300 \mu \mathrm{L}$ of $0.2 \mathrm{~mol} / \mathrm{L} \mathrm{CH}_{3} \mathrm{COONa}(\mathrm{pH} 5.2)$ and $75 \mu \mathrm{L}$ of $1 \mathrm{~mol} / \mathrm{L}$ acetic acid were added, bringing $\mathrm{pH}$ to 5.5. The content of each tube was then divided into 2 tubes $(250 \mu \mathrm{L} /$ tube $)$. In one of these tubes, trehalose concentration was determined by adding $15 \mu \mathrm{L}$ of $0.2 \mathrm{~mol} / \mathrm{L} \mathrm{CH}_{3} \mathrm{COONa}(\mathrm{pH} 8.0)$ and $3 \mu \mathrm{L}$ of porcine trehalase (Sigma-Aldrich). Following overnight incubation at $37 \pm 1{ }^{\circ} \mathrm{C}$, glucose was measured using an enzymatic kit (Wiener Lab, Rosario, Argentina). Glycogen content was determined by addition $10 \mu \mathrm{L}$ of an $\alpha$-amyloglucosidase solution ( $\sim 70 \mathrm{U} / \mathrm{mg}$ ) to the remaining tube. After overnight incubation at $57 \pm 1{ }^{\circ} \mathrm{C}$ glucose concentration was measured using the mentioned enzymatic kit.

\section{PYRUVATE KINASE ACTIVITY AND INTRACELLULAR OXIDOREDUCTASE COENZYMES LEVELS}

Pyruvate kinase (PK) activity, and levels of NADH/NAD and NADPH/NADP were measured spectrophotometrically as described in the corresponding kits protocols (SigmaAldrich MAK072, MAK037 and MAK312, respectively) in cell-free extracts of Y-7124 and HAJ grown in YPDX or $\mathrm{JCH}$, respectively. $\mathrm{PK}$ activity is reported as milliunit/mL, where one milliunit $(\mathrm{mU})$ of pyruvate kinase is defined as the amount of enzyme that will transfer a phosphate group from PEP to ADP to generate 1.0 nmole of pyruvate per minute at $25^{\circ} \mathrm{C}$.

\section{BIOETHANOL PRODUCTION EFFICIENCY}

The ethanologenic efficiencies of S. stipitis Y-7124 and HAJ clone were compared using two fermentation media: $100 \%$ $\mathrm{JCH}$ and semisynthetic medium YPDX $(0.5 \%$ w/v yeast extract, $0.5 \% \mathrm{w} / \mathrm{v}$ peptone, $0.4 \% \mathrm{w} / \mathrm{v}$ glucose, $4.0 \% \mathrm{w} / \mathrm{v}$ xylose). $100 \mathrm{~mL}$ Erlenmeyer flasks containing $80 \mathrm{~mL}$ of either JCH or YPDX were adjusted to $\mathrm{pH} 4.5$ and inoculated to an initial cell concentration of $1.0 \times 10^{6}$ cell $/ \mathrm{mL}$. After incubating in an orbital shaker at $28 \pm 1^{\circ} \mathrm{C}$ and $100 \mathrm{rpm}$ for $72 \mathrm{~h}$, samples were withdrawn from the cultures and then centrifuged at 7,500 $\mathrm{g}$ for $10 \mathrm{~min}$. Ethanol was quantified from the culture supernatants using an enzymatic kit (R-Biopharm AG, Darmstadt, Germany), and total reducing sugars were measured by the DNS method to determine volumetric production of ethanol, sugar consumption, volumetric productivity, and fermentation efficiency $(\mathrm{Fe})$. The latter was calculated according to the following formula: 


$$
F e=\frac{E}{S \times 0.511} \times 100 \%
$$

where $E$ is the final ethanol concentration in the fermented medium $[\mathrm{g} / \mathrm{L}] ; \mathrm{S}$ is total reducing sugars consumed $[\mathrm{g} / \mathrm{L}]$, and $0.511 \mathrm{~g} / \mathrm{g}$ is the maximum theoretical yield of ethanol from $1 \mathrm{~mol}$ of glucose or xylose.

\section{STATISTICAL ANALYSIS}

All experiments were performed in triplicate, unless stated otherwise. Data were analyzed by two-way ANOVA followed by Fisher's LSD (Least Significant Difference) test, using GraphPad Prism 6.01 (GraphPad Software, La Jolla, CA). Logarithmic transformation of CAT, SOD and ROS data was needed to comply with homoscedasticity. Values in graphics are shown as mean \pm standard error.

\section{Results and Discussion}

\section{STRAIN ADAPTATION IN JCH}

The adaptation of $S$. stipitis NRRL Y-7124 was performed in successive batch cultures with increasing concentrations of JCH. This procedure allowed the adaptation of the S. stipitis strain to the jojoba hydrolysate through metabolism adaptation or spontaneous mutations that could be driven by the inhibitors and toxic compounds present in this hydrolysate. As a result of this evolutionary adaptation strategy, the adapted clone HAJ was obtained, capable of attaining growth levels in $90 \% \mathrm{JCH}$ of $>4.0$ absorbance units (starting from $\mathrm{OD}_{600 \mathrm{~nm}} \approx 0.5$ ) within the first $24 \mathrm{~h}$ of culture, whereas the parental strain Y-7124 showed no growth until $48 \mathrm{~h}$ in the same culture medium.

\section{VIABILITY AND VITALITY UNDER STRESS CONDITIONS}

As shown in Fig. 1, all stressors tested significantly decreased viability and fermentative performance (vitality) of both strains in different percentages. Thus, viability values for strain Y-7124 ranged from below $7 \%$ survival for temperature and $13 \%$ for ethanol, up to $40 \%$ for vanillin, indicative that the most severe stresses, among those assayed concerning cell duplicative capacity, were thermal shock and ethanol, with phenolic stress being the less severe. On the other hand, compared to Y-7124, clone HAJ showed higher viability under all the stress conditions tested, from $\sim 2.0$ fold for ethanol and temperature stress up to $\sim 4.0$ fold for osmotic stress (Fig. la).

Preconditioning of HAJ by exposure to toxic compounds present in JCH seemed not to affect its metabolic performance, since vitality control values were similar in magnitude to those of Y-7124 (Fig. 1b). After stress treatment, the difference between strains became more pronounced, with HAJ exhibiting significantly higher vitality than Y-7124 under the same conditions, and most pronounced for ethanol ( $\sim 8.0$ fold higher).

HAJ exhibited significantly higher viability and vitality values than Y-7124 where stresses seemed to affect the fermentative performance more than its survival capacity. These results indicate that the adapted HAJ clone has a higher stress tolerance, evaluated as survival and mainly as metabolic robustness, than its isogenic parental strain. HAJ would thus be preferred to Y-7124 for ethanologenic fermentation, because the different stressful situations that yeasts could face during industrial cellulosic bioethanol production are less detrimental to its biocatalytic performance.

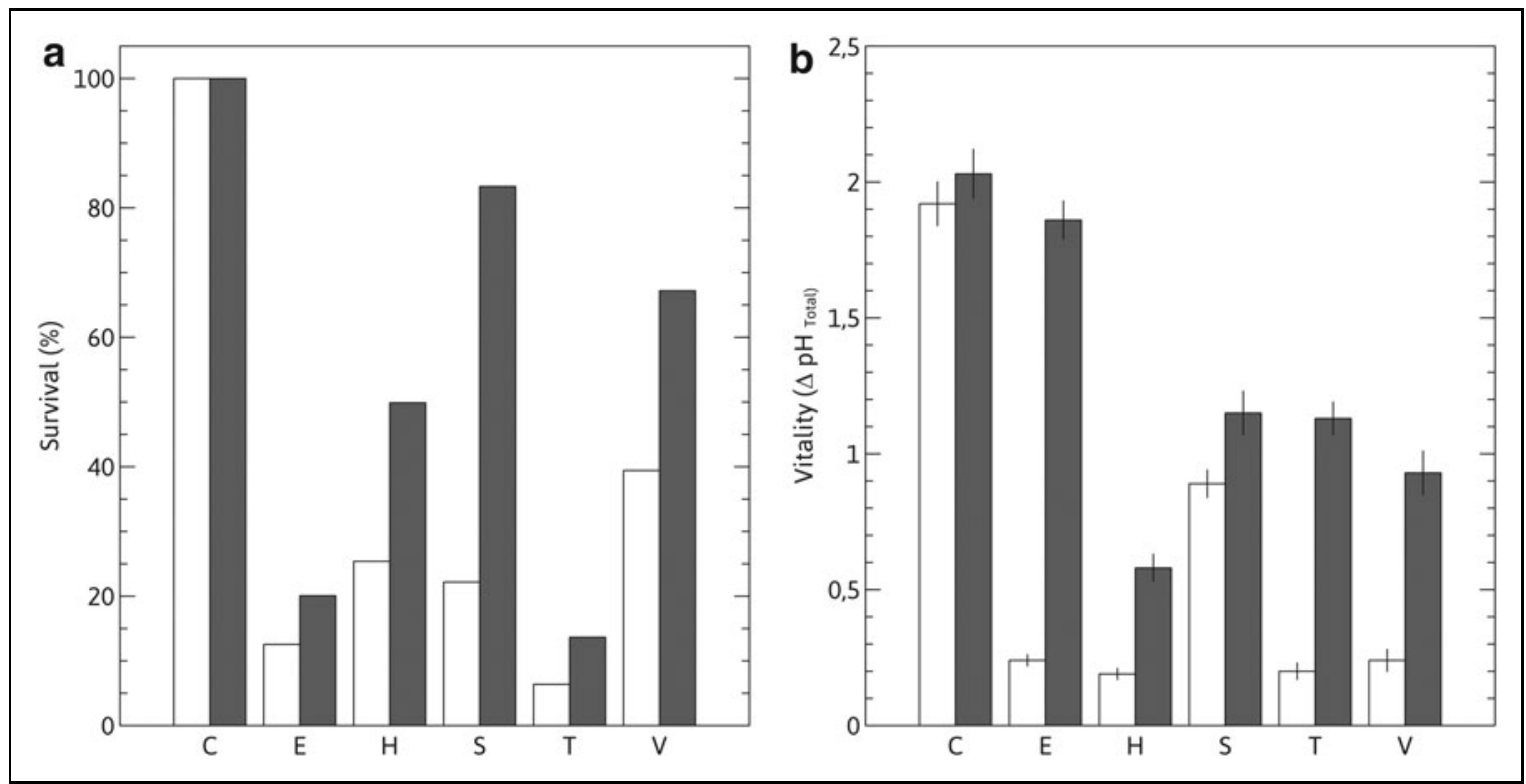

Fig. 1. Viability and vitality under stress conditions. (a) Cell viability, indicated as percentage of survival, and (b) vitality, shown as acidification power, determined after stress treatments for S. stipitis Y-7124 ( $\square$ ) and HAJ clone ( $\square$ ). C: control (without stress); E: ethanol; $H$ : oxidative stress; $S$ : osmotic shock; $T$ : thermal shock; and $V$ : phenolic acid. See Materials and Methods for stress conditions. 


\section{OXIDATIVE PARAMETERS: ROS AND ANTIOXIDATIVE ENZYMATIC ACTIVITY}

The stressful conditions applied produced an imbalance in the redox state of the cells, as depicted in Fig. 2a, where the intracellular ROS content of both strains are shown before and after being submitted to the different stresses assayed.

Upon exposition to the different stressors, ROS levels increased (Fig. 2a), in varying amounts depending on the stress applied and the yeast population being tested. While for Y-7124 intracellular ROS concentrations increased significantly after each treatment, the adapted clone ROS concentration incre- ments were only statistically significant for ethanol, which was the most oxidative condition among those tested, with a 15-fold increase over control (non-stressed) levels (Fig. 2a). Ethanol, followed by temperature- the most damaging stressing conditions assayed (Fig. 1) -were the highest ROS-generating stresses assayed, even when compared to the highly oxidative treatment with $\mathrm{H}_{2} \mathrm{O}_{2}$. They were at the same time the most harmful ones, generating the lower viability and vitality values reported for both strains (mainly for Y-7124, Fig. 1). All the stresses assayed increased ROS intracellular levels in both yeast populations, supporting the idea that oxidative stress could be a

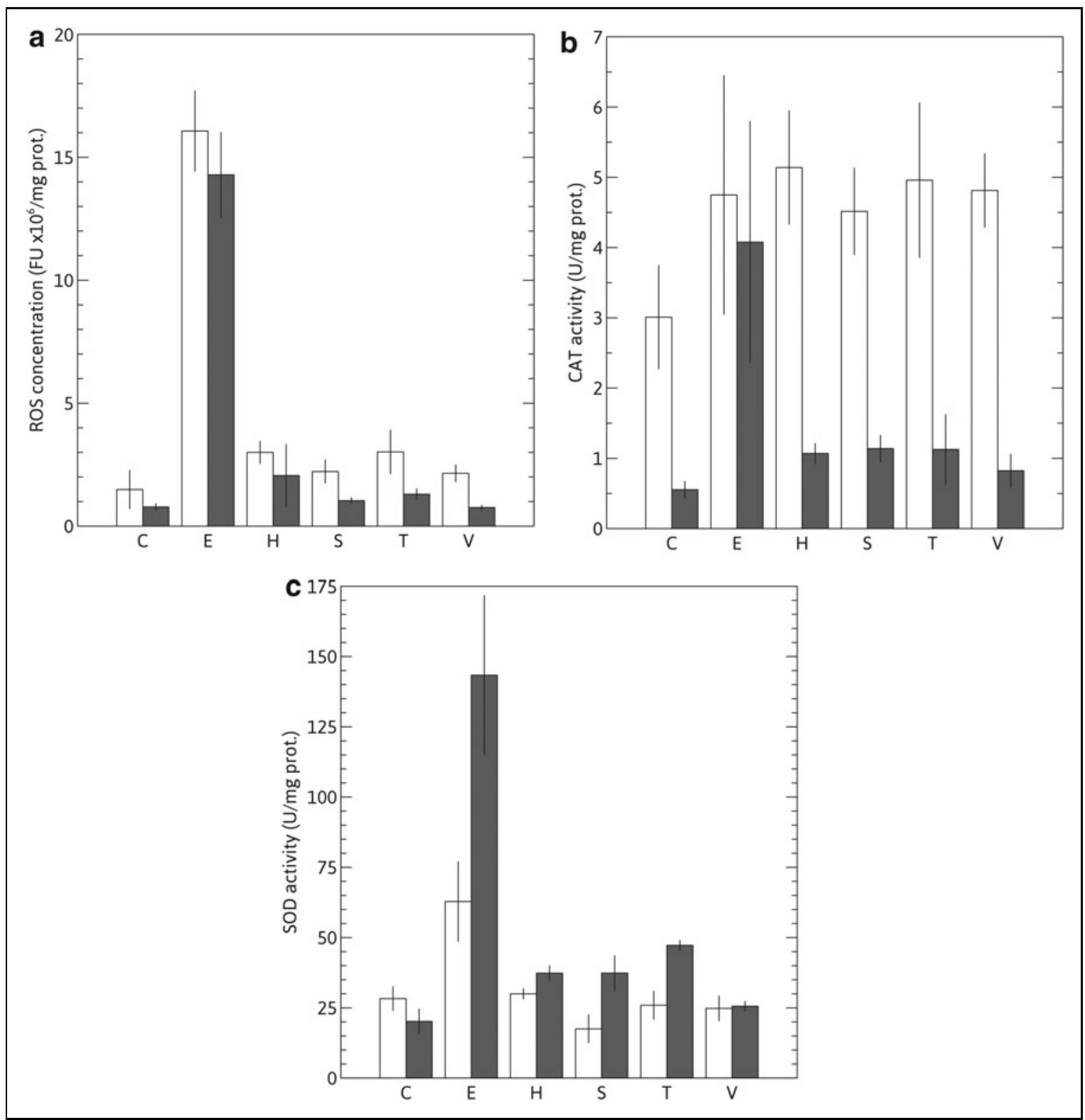

Fig. 2. Oxidative parameters. (a) ROS intracellular level, (b) catalase activity, and (c) superoxide dismutase activity, determined after stress treatments for S. stipitis Y-7124 ( $\square$ ) and HAJ clone ( $\square$ ). C: control (without stress); E: ethanol; H: oxidative stress; S: osmotic shock; $T$ : thermal shock; and V: phenolic acid. See Materials and Methods for stress conditions. 
cell-damaging mechanism common to all stresses tested. Compared with controls, ROS increase in HAJ after being subjected to each stress was 30-50\% lower than in Y-7124. This indicates that the defenses against oxidative attacks may be expected to act more efficiently in the adapted clone, possibly because this strain has developed a more effective ROSdetoxifying mechanism than the one present in the parental strain. To evaluate this hypothesis, we measured intracellular CAT and SOD enzymatic activities in both strains and their relationship with intracellular ROS levels after being subjected to the different stress conditions.

As shown in Fig. 2b, CAT activity in HAJ was negatively affected by the stress conditions faced during its adaptation in $\mathrm{JCH}$, since its activity in control cells (non-stressed) shows lower values than that of Y-7124 unstressed control. However, when both cell populations were submitted to stress, the relative increase in CAT enzymatic activity (compared to each control) was higher for the adapted strain. This was most notable for the more severe oxidative (ROS-generating) stresses assayed, i.e., ethanol ( $>7$-fold increase), sorbitol and temperature ( $\sim 2$-fold increase).

Concurrently with the observed values for CAT, SOD activity increase was more pronounced in HAJ, particularly after temperature and hydric stress treatments, e.g., ethanol and sorbitol, which were at the same time oxidative. As shown in Fig. 2c, SOD activity increased significantly in $\mathrm{HAJ}$ for all stresses, with this increase being higher with ethanol ( $\sim 7$ fold), temperature, and sorbitol ( $\sim 2-3$ fold). For Y-7124, only exposure to ethanol, the most oxidative stress assayed, seemed to elicit a rise in SOD levels (a 2-fold increase).

The increase of the enzymatic activities in HAJ does not elicit a complete reversal of the homeostatic redox state to the initial one. It does allow the adapted clone to withstand the increased levels of ROS, as shown by its higher values of viability and vitality compared to Y-7124, after both were challenged with the same stresses.

In this sense, our results are consistent with the principle of stress co-tolerance reported in Saccharomyces cerevisiae by different authors. ${ }^{14,36,37}$ The improved ability of the adapted clone to resist harsh conditions caused by various stresses could be associated with its capacity for ROS detoxification, concurring with previous reports in S. cerevisiae. ${ }^{14,20,22}$

\section{TREHALOSE AND GLYCOGEN LEVELS}

To evaluate other biochemical mechanisms reported to be involved in stress defense in yeasts, ${ }^{48}$ glycogen and trehalose intracellular levels were determined in S. stipitis Y-7124 and HAJ. As can be seen in Fig. 3, the non-stressed adapted clone showed glycogen levels higher, although not significantly different, than Y-7124, but nearly 5 times higher trehalose contents. This indicates that HAJ was submitted to mild stressful conditions during its adaptation process in $\mathrm{JCH}^{29}$ After that, treatment with different stresses made glycogen and trehalose levels increase, reaching higher levels in HAJ than in Y-7124, with sorbitol stress generating the highest significant values for both sugars (Fig. 3). Particularly, intracellular trehalose concentration in both strains was significantly higher (between 2- and 7-fold) than their respective controls for all the stresses, reaching its highest levels in the case of sorbitol (Fig. 3b). These results are consistent with those reported by other authors for yeasts, ${ }^{29}$ suggesting that the multi-tolerance to stress, and particularly to water deficiency stress in S. stipitis, could also be based on an increased synthesis and intracellular accumulation of both glycogen and, mainly, trehalose.

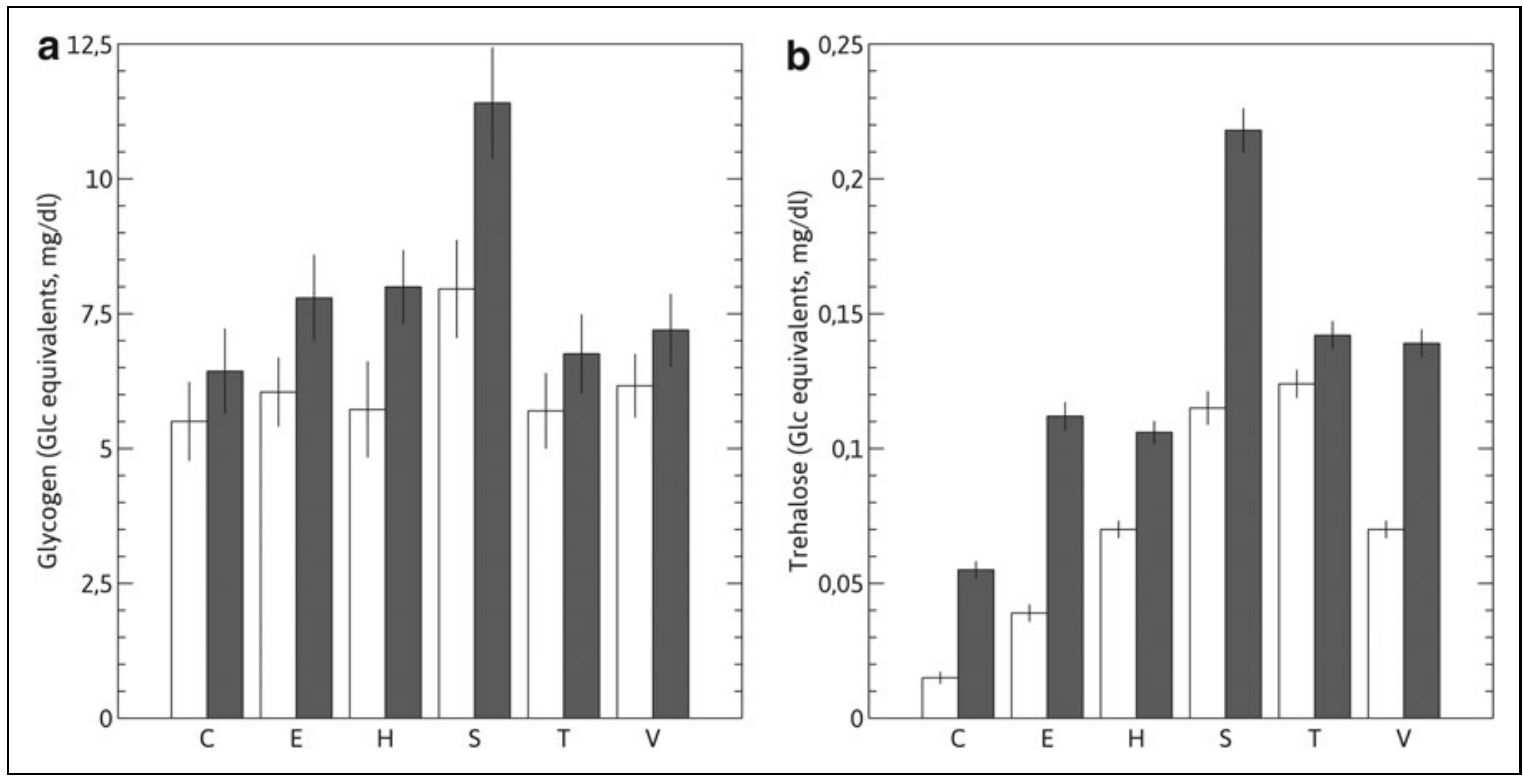

Fig. 3. Trehalose and glycogen levels. (a) Glycogen and (b) trehalose intracellular levels determined after stress treatments for $S$. stipitis Y-7124 ( $\square$ ) and HAJ clone ( $\square$ ). C: control (without stress); E: ethanol; H: oxidative stress; S: osmotic shock; $T$ : thermal shock; and V: phenolic acid. See Materials and Methods for stress conditions. Glycogen and trehalose levels are expressed as glucose concentration $(\mathrm{mg} / \mathrm{dl})$. 
Table 1. Fermentation Parameters for Ethanol Production Using the Parental Strain S. stipitis NRRL Y-7124 and Adapted Clone HAJ

\begin{tabular}{l|c|c|c|c|c} 
& \multicolumn{2}{c|}{ Y-7124 } & \multicolumn{2}{c}{ HAJ } \\
\multicolumn{1}{c|}{ PARAMETER } & YPDX & JCH & YPDX & JCH \\
\hline Ethanol production $\left(g_{p} / L\right)$ & $12.52 \pm 0.62$ & $1.22 \pm 0.28$ & $10.02 \pm 0.45$ & $3.49 \pm 0.14$ \\
\hline Sugar consumed $(\%)$ & $59.96 \pm 1.04$ & $12.36 \pm 0.19$ & $51.05 \pm 1.02$ & $25.71 \pm 0.46$ \\
\hline$Y_{p / s}\left(g_{\text {EtoH }} / g_{s}\right)$ & $0.21 \pm 0.01$ & $0.10 \pm 0.01$ & $0.20 \pm 0.01$ & $0.14 \pm 0.01$ \\
\hline$Q_{p}$ av $\left(g_{p} / L \cdot h\right)$ & $0.17 \pm 0.01$ & $0.02 \pm 0.01$ & $0.14 \pm 0.01$ & $0.05 \pm 0.01$ \\
\hline Fermentation efficiency $(\%)$ & $93.02 \pm 1.36$ & $43.88 \pm 0.73$ & $87.47 \pm 1.16$ & $60.57 \pm 0.91$ \\
\hline$Y-7124: p a r e n t a t$
\end{tabular}

Y-7124: parental strain; HAJ: adapted clone; YPDX: medium containing yeast extract, peptone, dextrose and xylose; $\mathrm{JCH}$ : jojoba cake hydrolysate; $Y_{p / s}$ : Ethanol yield coefficient based on total sugar consumption $\left(g_{p} / g_{s}\right) ; O p$ av: Average volumetric productivity determined as the average value of ethanol produced in function of fermentation time $\left(g_{p} / L \cdot h\right)$; Op max: Maximum volumetric productivity determined as the maximum value of ethanol produced in function of fermentation time $\left(g_{p} / L \cdot h\right)$; Ethanologenic efficiency $(\%)$ : sugar conversion efficiency (i.e., theoretical yield), calculated as ethanol yield/0.51) x 100. See Materials and Methods for details.

\section{PYRUVATE KINASE ACTIVITY AND INTRACELLULAR OXIDOREDUCTASE COENZYMES LEVELS}

For Y-7124 control extracts, the following values were found (in $\mu \mathrm{mol} / \mathrm{g}$ cell dry weight): $0.43 / 3.5$ for NADH/NAD and $0.07 /$ 0.46 for NADPH/NADP. Similar values $(\sim+/-5 \%$ difference $)$ were found in HAJ control extracts. PK activity remained at $\sim 4.40 \pm 0.18 \mathrm{mU} / \mathrm{mL}$ for both strains. No significant differ- ences in those values were found after ethanol exposure (the most oxidative stress reported here) for either the parental strain or the adapted clone. These results suggest that the significant increase in intracellular trehalose concentration observed after stress treatment (see previous section) did not have a significant impact on the glycolytic pathway of the strains used.

\section{FERMENTATION PERFORMANCE IN JCH}

The adapted clone HAJ and the parental strain Y-7124 were compared for ethanol production in non-detoxified and non-supplemented $\mathrm{JCH}$ and YPDX semisynthetic medium. As shown in Table 1 and Fig. 4, the HAJ clone was well adapted to the hydrolysate fermentation medium, as shown by the kinetic parameters, exhibiting volumetric production, sugar consumption, volumetric productivity, yield values and kinetic parameters up to 3-fold higher than those of Y-7124, despite higher sugar consumption by the latter. However, bioethanol production efficiency of the parental strain in the control medium YPDX remained slightly higher than that of the adapted clone $(93.02 \%$ vs $87.47 \%$ efficiency, for Y-7124 and HAJ strains, respectively).

These results show that the adapted clone exhibited higher ethanologenic efficiency compared to the parental strain when using a non-supplemented and non-detoxified lignocellulosic hydrolysate as a fermentation medium. Its greater stress tolerance after adaptation would thus allow it to obtain higher

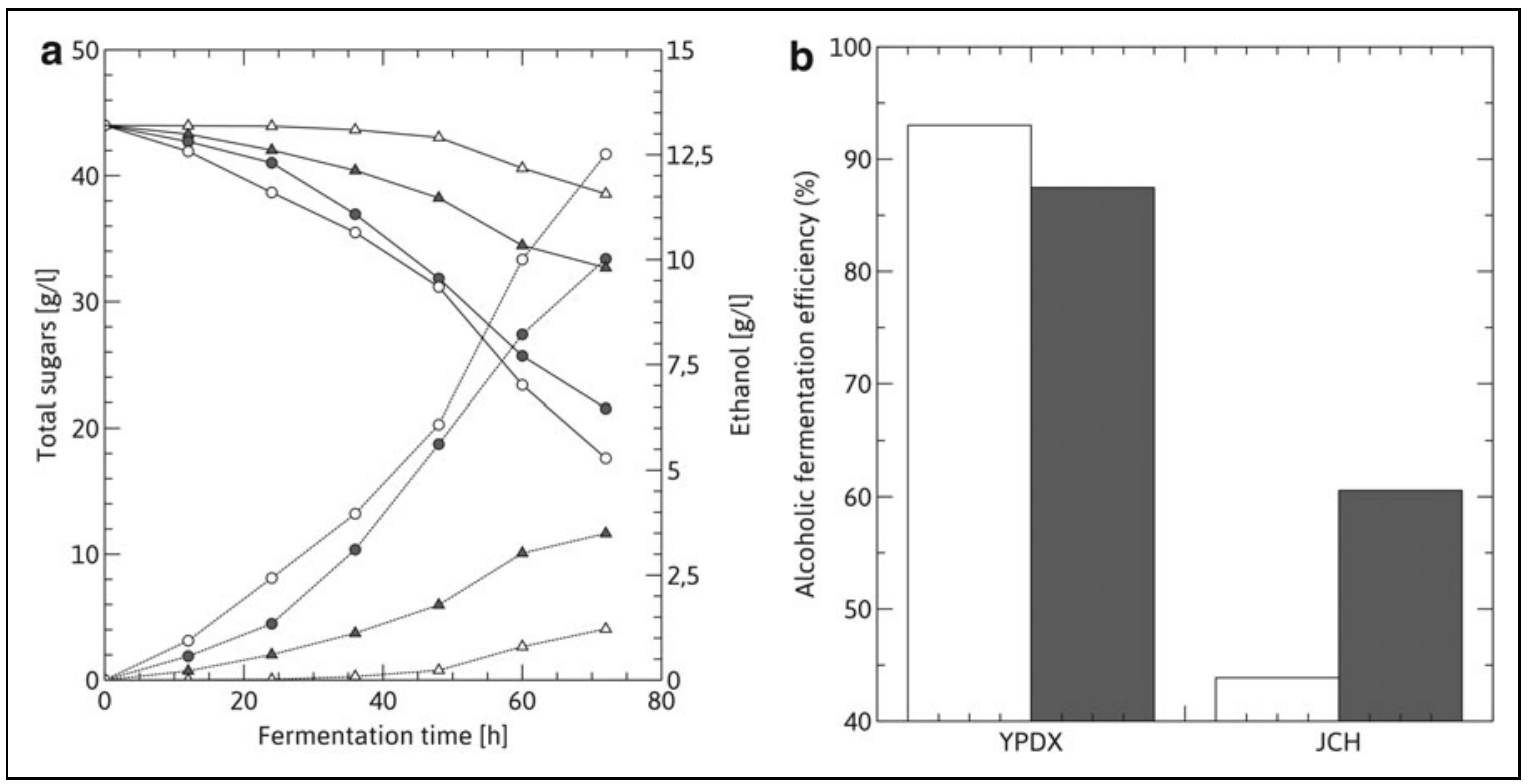

Fig. 4. Fermentation performance in jojoba-cake hydrolysate. (a) Total sugar consumption (solid lines) and ethanol production (dotted lines) in YPDX (circles) or JCH (triangles) by S. stipitis Y-7124 (white) and HAJ (gray); (b) Alcoholic fermentation efficiency, expressed as percentage of the maximum theoretical yield based on glucose consumption, determined for S. stipitis Y-7124 ( $\square$ ) and HAJ clone ( $\square$ ). YPDX: medium containing yeast extract, peptone, dextrose and xylose; JCH: jojoba cake hydrolysate. See Materials and Methods for details. 


\section{NOVELLI POISSON ET AL.}

ethanol production levels in such hydrolysates, turning secondgeneration industrial bioethanol production more economically viable by saving time and costs of medium detoxification.

\section{Conclusions}

The robustness of the evolutionarily adapted strain of $S$. stipitis presented in this work was associated with its higher capacity (compared to its parental isogenic strain) to tolerate the different oxidative (ROS-generating) stresses found during a standard industrial bioprocess of cellulosic ethanol production. This fact is indicative that there might be a common basis for the mechanism of stress damage and for its repair. Stress tolerance was associated, in turn, to the activation of the antioxidant enzymes catalase and superoxide dismutase. The latter's activation is quantitatively related to the level of oxidative stress applied, indicating that $\mathrm{O}_{2}{ }^{\bullet-}$ plays an important role in the oxidative stress of this strain.

Cell membrane-protecting molecules, like trehalose, increased their concentration in response to the mildly-stressing adaptive process, increasing even further after more severe stress challenges. The highest intracellular trehalose levels in the adapted strain were reached under osmotic stress, indicative of the specificity between the type of stress applied and the concentration of that disaccharide.

As a whole, it can be concluded that a stress-tolerant yeast strain used in cellulosic ethanol production has to present high antioxidative defenses, and that attaining high intracellular levels of cell membrane protectants like trehalose is a goal to reach if a robust strain is desired. Our results also show that the evolutionarily adapted strain of $S$. stipitis could be used industrially to efficiently produce cellulosic ethanol from a nondetoxified agro-industrial fermentation medium. This is mainly due to its increased tolerance to osmotic and ethanol stresses, the two main stressful conditions that prevent the industrial use of this yeast species in ethanologenic fermentations.

\section{Acknowledgments}

The authors wish to thank Dr. D. Wassner for providing the jojoba cake, and Dr. Ma. T. Rimoldi for oxidoreductase coenzymes and pyruvate kinase activity measurement. We also thank Dr. Susana Passeron for the critical reading of the English manuscript.

\section{Author Disclosure Statement}

No competing financial interests exist.

\section{Funding Information}

This work was supported by grants from PIP 2012-2014 and by PIO CONICET-UNSAM 2015-2017 Argentina (Consejo Nacional de Investigaciones Científicas y Técnicas).

\section{REFERENCES}

1. Hahn-Hägerdal B, Pamment N. Microbial Pentose Metabolism. In: Finkelstein M, McMillan JD, Davison BH, Evans B, eds. Proceedings of the Twenty-Fifth Symposium on Biotechnology for Fuels and Chemicals Held May 4-7, 2003, Breckenridge, CO. Humana Press; 2004:1207-1209. doi:10.1007/978-1-59259837-3_97
2. van Maris AJA, Winkler AA, Kuyper M, de Laat WTAM, van Dijken JP, Pronk JT. Development of efficient xylose fermentation in Saccharomyces cerevisiae: Xylose isomerase as a key component. In: Olsson L, ed. Biofuels. Vol 108. Springer Berlin Heidelberg; 2007:179-204. doi:10.1007/10_2007_057

3. Agbogbo FK, Coward-Kelly G. Cellulosic ethanol production using the naturally occurring xylose-fermenting yeast, Pichia stipitis. Biotechnol Lett 2008;30(9): 1515-1524. doi:10.1007/s10529-008-9728-z

4. Cho JY, Jeffries TW. Pichia stipitis genes for alcohol dehydrogenase with fermentative and respiratory functions. App/ Environ Microbiol 1998;64(4): 1350-1358.

5. Jeffries TW, Jin Y-S. Metabolic engineering for improved fermentation of pentoses by yeasts. Appl Microbiol Biotechnol 2004;63(5):495-509. doi: 10.1007/s00253-003-1450-0

6. Slininger PJ, Dien BS, Gorsich SW, Liu ZL. Nitrogen source and mineral optimization enhance $d$-xylose conversion to ethanol by the yeast Pichia stipitis NRRL Y-7124. App/ Microbiol Biotechnol 2006;72(6):1285-1296. doi:10.1007| s00253-006-0435-1

7. Hijosa-Valsero M, Paniagua-García Al, Díez-Antolínez R. Biobutanol production from apple pomace: The importance of pretreatment methods on the fermentability of lignocellulosic agro-food wastes. Appl Microbiol Biotechnol 2017;101(21):8041-8052. doi:10.1007/s00253-017-8522-z

8. Jönsson $\sqcup$, Martin C. Pretreatment of lignocellulose: Formation of inhibitory by-products and strategies for minimizing their effects. Bioresour Technol 2016;199:103-112. doi:10.1016/j.biortech.2015.10.009

9. Çakar Z, Seker U, Tamerler C, Sonderegger M, Sauer U. Evolutionary engineering of multiple-stress resistant. FEMS Yeast Res 2005;5(6-7):569-578. doi:10.1016/ j.femsyr.2004.10.010

10. Wallace-Salinas V, Gorwa-Grauslund MF. Adaptive evolution of an industrial strain of Saccharomyces cerevisiae for combined tolerance to inhibitors and temperature. Biotechnol Biofuels 2013;6(1):151. doi:10.1186/1754-68346-151

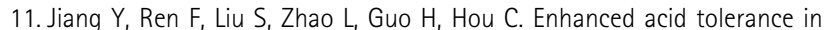
Bifidobacterium longum by adaptive evolution: Comparison of the genes between the acid-resistant variant and wild-type strain. J Microbiol Biotechnol 2016;26(3):452-460. doi:10.4014/jmb.1508.08030

12. Baek SH, Kwon EY, Kim YH, Hahn JS. Metabolic engineering and adaptive evolution for efficient production of D-lactic acid in Saccharomyces cerevisiae. Appl Microbiol Biotechnol 2016;100(6):2737-2748. doi:10.1007/s00253-0157174-0

13. González-Ramos D, Gorter de Vries AR, Grijseels SS, et al. A new laboratory evolution approach to select for constitutive acetic acid tolerance in Saccharomyces cerevisiae and identification of causal mutations. Biotechnol Biof 2016;9(1). doi:10.1186/s13068-016-0583-1

14. Gurdo N, Novelli Poisson GF, Juárez ÁB, Rios de Molina MC, Galvagno MA. Improved robustness of an ethanologenic yeast strain through adaptive evolution in acetic acid is associated with its enzymatic antioxidant ability. $J$ Appl Microbiol 2018;125(3):766-776. doi:10.1111/jam.13917

15. Gutteridge JMC, Halliwell B. The measurement and mechanism of lipid peroxidation in biological systems. Trends Biochem Sci 1990;15(4):129-135. doi: 10.1016/0968-0004(90)90206-0

16. Yang $\mathrm{M}-\mathrm{H}$, Schaich KM. Factors affecting DNA damage caused by lipid hydroperoxides and aldehydes. Free Radical Biol Med 1996;20(2):225-236. doi: 10.1016/0891-5849(95)02039-X

17. Mendes-Ferreira A, Sampaio-Marques B, Barbosa $C$, et al. Accumulation of nonsuperoxide anion reactive oxygen species mediates nitrogen-limited alcoholic fermentation by Saccharomyces cerevisiae. App/ Environ Microbio/ 2010;76(24): 7918-7924. doi:10.1128/AEM.01535-10

18. Grant CM, Maclver FH, Dawes IW. Glutathione is an essential metabolite required for resistance to oxidative stress in the yeastSaccharomyces cerevisiae. Curr Gene 1996;29(6):511-515. doi:10.1007/BF02426954

19. Costa V, Amorim MA, Reis E, Quintanilha A, Moradas-Ferreira P. Mitochondrial superoxide dismutase is essential for ethanol tolerance of Saccharomyces 


\section{STRESS TOLERANCE IN ADAPTED STRAIN OF S. STIPITIS FOR BIOETHANOL PRODUCTION}

cerevisiae in the post-diauxic phase. Microbiology 1997;143(5):1649-1656. doi: 10.1099/00221287-143-5-1649

20. Trotter EW, Grant CM. Overlapping roles of the cytoplasmic and mitochondrial redox regulatory systems in the yeast Saccharomyces cerevisiae. Eukaryotic Cell 2005;4(2):392-400. doi:10.1128/EC.4.2.392-400.2005

21. Moradas-Ferreira $P$, Costa $V$, Piper $P$, Mager $W$. The molecular defences against reactive oxygen species in yeast. Molecul Microbiol 1996;19(4):651-658. doi: 10.1046/j.1365-2958.1996.403940.x

22. Moradas-Ferreira P, Costa V. Adaptive response of the yeast Saccharomyces cerevisiae to reactive oxygen species: Defences, damage and death. Redox Rep 2000;5(5):277-285. doi:10.1179/135100000101535816

23. Mager WH, Ferreira PM. Stress response of yeast. Biochem J 1993;290(1):1-13. doi:10.1042/bj2900001

24. Jamieson DJ. Oxidative stress responses of the yeast Saccharomyces cerevisiae. Yeast 1998;14(16):1511-1527. doi:10.1002/(SICI) 1097-0061(199812)14:16 $<1511:: A I D-Y E A 356>3.0 . C 0 ; 2-S$

25. Estruch F. Stress-controlled transcription factors, stress-induced genes and stress tolerance in budding yeast. FEMS Microbiol Rev 2000;24(4):469-486. doi: 10.1016/S0168-6445(00)00035-8

26. Wiemken A. Trehalose in yeast, stress protectant rather than reserve carbohydrate. Antonie van Leeuwenhoek 1990;58(3):209-217. doi:10.1007| BF00548935

27. Thevelein JM. Regulation of Trehalose Metabolism and Its Relevance to cell Growth and Function. In: Brambl R, Marzluf GA, eds. Biochemistry and Molecular Biology. Springer Berlin Heidelberg; 1996:395-420. doi:10.1007/9783-662-10367-8_19

28. Argüelles JC. Physiological roles of trehalose in bacteria and yeasts: A comparative analysis. Arch Microbiol 2000;174(4):217-224. doi:10.1007| s002030000192

29. Benaroudj N, Lee DH, Goldberg AL. Trehalose accumulation during cellular stress protects cells and cellular proteins from damage by oxygen radicals. J Biol Chem 2001;276(26):24261-24267. doi:10.1074/jbc.M101487200

30. Singer MA, Lindquist $S$. Thermotolerance in Saccharomyces cerevisiae: the Yin and Yang of trehalose. Trends Biotechnol 1998;16(11):460-468. doi:10.1016/ S0167-7799(98)01251-7

31. González-Párraga P, Hernández JA, Argüelles JC. Role of antioxidant enzymatic defences against oxidative stress $\left(\mathrm{H}_{2} \mathrm{O}_{2}\right)$ and the acquisition of oxidative tolerance in Candida albicans: Antioxidant enzymes and oxidative stress in Candida albicans. Yeast 2003;20(14):1161-1169. doi:10.1002/yea.1029

32. Silljé HH, Paalman JW, ter Schure EG, et al. Function of trehalose and glycogen in cell cycle progression and cell viability in Saccharomyces cerevisiae. J Bacteriol 1999;181(2):396-400.

33. Zhang $X$, Zhang $Y$, Li H. Regulation of trehalose, a typical stress protectant, on central metabolisms, cell growth and division of Saccharomyces cerevisiae CEN.PK113-7D. Food Microbiol 2020;89:103459. doi:10.1016/j.fm.2020.103459

34. Schüller C, Brewster JL, Alexander MR, Gustin MC, Ruis H. The HOG pathway controls osmotic regulation of transcription via the stress response element (STRE) of the Saccharomyces cerevisiae CT1 gene. The EMBO J 1994;13(18): 4382-4389. doi:10.1002/j.1460-2075.1994.tb06758.x

35. Mager WH, De Kruijff AJ. Stress-induced transcriptional activation. Microbiol Rev 1995;59(3):506-531.
36. Lewis JG, Learmonth RP, Watson K. Induction of heat, freezing and salt tolerance by heat and salt shock in Saccharomyces cerevisiae. Microbiology 1995;141(3):687-694. doi:10.1099/13500872-141-3-687

37. Attfield PV. Stress tolerance: The key to effective strains of industrial baker's yeast. Nature Biotechnol 1997;15(13):1351-1357. doi:10.1038/nbt12971351

38. Shi J, Zhang M, Zhang L, Wang P, Jiang L, Deng H. Xylose-fermenting Pichia stipitis by genome shuffling for improved ethanol production: Pichia stipitis for improved ethanol production. Microb Biotechnol 2014;7(2):90-99. doi:10.1111/ 1751-7915.12092

39. Deschatelets $L$, Yu EKC. A simple pentose assay for biomass conversion studies. Appl Microbiol Biotechnol 1986;24(5):379-385. doi:10.1007/BF00294594

40. Singleton VL, Orthofer R, Lamuela-Raventós RM. Analysis of total phenols and other oxidation substrates and antioxidants by means of folin-ciocalteu reagent. In: Methods in Enzymology. Vol 299. Elsevier; 1999:152-178. doi: 10.1016/S0076-6879(99)99017-1

41. Martinez A, Rodriguez ME, York SW, Preston JF, Ingram LO. Use of UV absorbance to monitor furans in dilute acid hydrolysates of biomass. Biotechnol Progr 2000;16(4):637-641. doi:10.1021/bp0000508

42. Adams MR, Moss MO. Food Microbiology. 2nd ed. Royal Society of Chemistry; 2000.

43. Opekarová M, Sigler K. Acidification power: Indicator of metabolic activity and autolytic changes in Saccharomyces cerevisiae. Folia Microbiologica 1982; 27(6):395-403. doi:10.1007/BF02876450

44. Zhang L, Onda K, Imai R, Fukuda R, Horiuchi H, Ohta A. Growth temperature downshift induces antioxidant response in Saccharomyces cerevisiae. Biochem Biophysical Res Comm 2003;307(2):308-314. doi:10.1016/S0006291X(03)01168-9

45. Aebi H. Catalase in vitro. Meth Enzymol 1984;105:121-126.

46. Beauchamp C, Fridovich I. Superoxide dismutase: Improved assays and an assay applicable to acrylamide gels. Anal Biochem 1971;(44):276-287.

47. Bradford M. A rapid and sensitive method for the quantitation of microgram quantities of protein utilizing the principle of protein-dye binding. Anal Biochem 1976;72(1-2):248-254. doi:10.1006/abio.1976.9999

48. Parrou JL, François J. A simplified procedure for a rapid and reliable assay of both glycogen and trehalose in whole yeast cells. Anal Biochem 1997;248(1): 186-188. doi:10.1006/abio.1997.2138

Address correspondence to: Miguel A. Galvagno

Instituto de Investigaciones Biotecnológicas Universidad Nacional de San Martín-Consejo Nacional de Investigaciones Cientificas y Técnicas Av. 25 de Mayo y Francia CP(1650), San Martín, Buenos Aires Argentina

Phone: +54 (11) 4006-1500

E-mail: miguelgalvagno@gmail.com 